\title{
Diagnóstico diferencial de la tos crónica en pediatría
}

\author{
Miles Weinberger MD'
}

1 Professor of Pediatrics. Pediatric Allergy \& Pulmonary Division. University of lowa Children's Hospital.

\section{DIFFERENCIAL DIAGNOSIS OF CHRONIC COUGH IN CHILDREN}

Chronic cough is a common cause of outpatient consultation. It is a source of distress for patients and parents, and in some cases it resolves spontaneously, without finding etiology. Professor Miles Weinberger emphasizes the importance of exhaustive medical record to characterize cough and associated signs, allowing us to identify typical patterns of some diseases.

Key words: Chronic cough, differencial diagnoses

\section{RESUMEN}

La tos crónica es una causa frecuente de consulta a nivel ambulatorio. Es motivo de angustia para pacientes y padres, y en algunos casos se resuelve espontáneamente, sin lograr precisar su etiología. El Profesor Miles Weinberger destaca la importancia de realizar una acuciosa historia clínica para caracterizar la tos y su signología asociada, lo que permite identificar patrones típicos de algunas enfermedades.

Palabras clave: Tos crónica, diagnóstico diferencial.

\section{INTRODUCCIÓN}

La tos es un síntoma común y molesto. La tos de curso agudo es más frecuente, y se debe habitualmente a una infección respiratoria viral alta (resfrío común). Algunos niños presentan tos aguda en forma recurrente, como manifestación frecuente de asma especialmente en edad pre-escolar. La tos crónica es particularmente problemática; en pediatría se le define como aquella que se mantiene por más de cuatro semanas.

En un grupo de 190 niños derivados a un centro terciario en Brisbane, Australia, se estudió la morbilidad por tos crónica. Más del $80 \%$ habían consultado 5 veces, y $53 \%$ más de 10 veces. El promedio de edad de los niños era de 2,6 años. Los síntomas tenían un impacto considerable en el sueño y la asistencia escolar ${ }^{(1)}$. El mismo grupo también refirió la etiología de la tos crónica en los principales centros de referencia en Australia(2).

\section{EVALUACIÓN DE LA TOS CRÓNICA EN NIÑOS BASADA EN LA EVIDENCIA}

El propósito de esta revisión es proporcionar una aproximación con relevancia clínica para identificar la causa de tos

Correspondencia:

Miles Weinberger MD

E-mail: contacto@neumologia-pediatrica.cl

Versión original en inglés. Tema presentado por Dr. Miles Weinberger en el IX Congreso de la Sociedad Chilena de Neumología Pediátrica, 2013, y revisión solicitada para su publicación en la revista Neumología Pediátrica

Traducción y resumen: Dra. Solange Caussade crónica en pediatría, guiar el manejo de los sindromes de tos y discutir las causas controversiales de tos. Se presentan etiologías precisas ilustrando para cada una sus hechos distintivos. Las causas más frecuentes de tos crónica se presentan en un algorritmo de diagnóstico utilizado por la División Alérgica, Inmunológica y Pulmón de la Universidad de lowa $(\text { Tabla I) })^{(2)}$.

\section{Síndrome de tos de hábito}

Antes de someter al paciente a mayor estudio diagnóstico y medicación, se debe considerar la posibilidad de tos de hábito. Esta, en su forma clásica, se caracteriza por un sonido repetitivo, a menudo fuerte, áspero, como un ladrido. Es por eso que se le ha descrito a veces como "tos de perro" o "tos de foca".

\section{Síndrome de Pertussis}

La Bordetella pertussis, el principal agente infeccioso causante de la clásica tos convulsiva, es altamente contagiosa y debería estar siempre en consideración debido a su importancia en la salud pública. El aumento del rechazo a la vacunación y la aparente disminución en la duración de la eficacia de la nueva vacuna acelular han sido asociados a numerosas epidemias locales ${ }^{(3)}$. También conocida como tos de los 100 días, la infección por Pertussis se caracteriza por una tos áspera, no productiva, espasmódica, y que se asocia frecuentemente a náuseas y vómitos post-tusivas.

\section{Traqueomalacia}

El colapso dinámico de la tráquea también puede causar tos. Esto se debería al contacto repetido de las superficies anterior y posterior de la tráquea, lo que causa irritación de esa zona. La tos frecuentemente es parecida a un ladrido, semejante al croup (laringotraqueobronquitis). 
Tabla I. Secuencia de evaluación, una vez se haya obtenido un historial minucioso, incluyendo la edad de inicio, duración, otros problemas clínicos y la respuesta a la medicación
A. Tos ausente durante el sueño indica probabilidad de Síndrome de tos de hábito
B. Tos presente por menos de 3 meses, sobre todo espasmódica, requiere considerar Pertussis
C. Tos en el lactante durante la alimentación justifica un estudio de deglución
D. Tos presente desde el período neonatal, historia de taquinea transitoria en el recién nacido, otitis media crónica justifica considerar disquinesia ciliar primaria
E. Cese de la tos después de curso corto de corticosteroides vía oral concuerda con asma; la evaluación ulterior puede determinar un plan de tratamiento adecuado
F. Intento fallido de detener la tos con el corticosteroide oral justifica evaluación ulterior
I. Hallazgos en Radiografía de tórax
a. Hiperinsuflación localizada, considerar aspiración de cuerpo extraño-considerar broncoscopia rígida
b. Signos sugerentes de inflamación de las vías aéreas o de bronquiectasis justifica un test de sudor en búsqueda de fibrosis quística
c. Situs inversus totalis sugiere una probabilidad de DCP
d. Rayos-x de pecho normales justifican evaluación ulterior

2. La fibrobroncoscopía con lavado broncoalveolar puede determinar lo siguiente:

a. Malacia de las vías aéreas, tráquea o bronquios

b. Bronquitis bacteriana prolongada

\section{Trastorno de deglución}

En algunos lactantes neurológicamente sanos hay paso de líquido a la parte superior de la tráquea, lo que causa tos. El contenido aspirado no permanece en la vía aérea y la retención transitoria no es dañina pero puede causar tos crónica. El estudio de deglución podría identificar el problema. Como estos lactantes tienen un reflejo efectivo de tos, no están en riesgo de neumonitis o neumonía crónica por aspiración. El tratamiento generalmente consiste en espesar los alimentos, rara vez se indican otras alternativas ya que este desorden de desarrollo mejora con la edad.

\section{Disquinesia ciliar primaria (DCP)}

Esta es una enfermedad poco frecuente cuya prevalencia es de alrededor de 1/15.000. Es de carácter recesivo y se produce ausencia o descoordinación del movimiento ciliar ${ }^{(4)}$. Más de un $80 \%$ de los lactantes con DCP presentan distress neonatal transitorio, lo que sugiere un rol de la función ciliar en la eliminación del líquido pulmonar luego del nacimiento. La tos crónica y las infecciones óticas recurrentes comienzan en período de lactante y continúan de manera constante de por vida. La acumulación de mucus en la vía aérea causa tos crónica húmeda. La mitad de los afectados tienen situs inversus totalis como consecuencia de la probable necesidad de movimiento ciliar fetal para determinar lateralización. La ausencia de movimiento ciliar determinaría esta lateralización de manera aleatoria. A pesar de la tos crónica, el crecimiento y desarrollo son normales y la progresión hacia la cronicidad es mucho más lenta que en la fibrosis quística. En el esputo no es frecuente encontrar bacterias patógenas, lo más frecuente es el hallazgo de Estreptococo $\alpha$-hemolítico y neutrófilos. Otras manifestaciones clínicas de DCP son la otitis media crónica debida a disfunción de la trompa de Eustaquio y la infertilidad masculina.

\section{Aspiración de cuerpo extraño}

La inhalación de un cuerpo extraño puede resultar en su retención durante meses o incluso años en ciertos casos, pero la tos crónica es una manifestación poco frecuente(5). Las formas de presentación más frecuentes son neumonía recurrente, hiperinsuflación lobar o segmentaria, y la atelectasia. Si el cuerpo extraño es retenido por un período largo, pueden aparecer bronquiectasias. Los cuerpos extraños más comunes son maníes pero casi cualquier objeto pequeño puesto en la boca del niño puede ser aspirado. El material aspirado vegetal (maní o plástico) no es radiopaco. Cuando se han descartado otras causas de tos crónica corresponde realizar una broncoscopía para buscar cuerpo extraño en la vía aérea.

\section{CAUSAS INUSUALES DE TOS CRÓNICA}

Algunas causas inusuales de tos crónica observadas en nuestro Servicio son:

Acalasia: Alteración de la motilidad esofágica debido a la ausencia de inervación muscular del esfínter esofágico inferior determinando dilatación del esófago proximal. Observamos dos casos en quienes la tos crónica era consecuencia de la compresión traqueal secundaria a la dilatación del esófago ${ }^{(6)}$.

Otra causa poco común de tos, que fue vista junto con otorrinolaringólogos, fue la provocada por gran hipertrofia de amígdalas palatinas que comprimían la epiglotis ${ }^{(7)}$. Otro caso fue el de un niño de 4 años quien presentaba tos crónica, destacando en su anamnesis la sensación de cuerpo extraño en la faringe; la causa era el contacto de la úvula con epiglotis, resolviéndose la tos luego de la uvulectomía(8). 


\section{CAUSAS CONTROVERSIALES DE TOS}

Hay múltiples causas de tos crónica que no poseen argumentos válidos para explicarlas. Éstas incluyen el reflujo gastro-esofágico (RGE), síndrome de tos por enfermedad de vía aérea superior, el síndrome de goteo pos-nasal, y la sinusitis.

El RGE es el preferido a pesar de los datos que tiene en su contra ${ }^{(9,10)}$. Aunque existe una relación certera entre el RGE y la tos crónica por varias causas, incluidas el asma y la fibrosis quística, no hay evidencia de que el tratamiento con inhibidores de bomba de protones disminuya la tos crónica. Las fuertes impresiones de algunos y varios reportes anecdóticos no controlados sugieren que tal vez haya una pequeña sub-población en la cual el GER produciría tos, pero no sabemos actualmente cómo identificar estos pacientes. Mientras tanto, las pruebas terapéuticas con inhibidores de bomba de protones para la tos crónica son considerados poco razonables.

Varios autores revisaron el síndrome de tos de las vías aéreas superiores y el goteo post-nasal, sin encontrar evidencia alguna para apoyar a éstos como causa de tos crónica ${ }^{(1-13)}$. Así como con el RGE, se puede asociar la tos crónica con rinitis y con la opacidad radiológica de los senos paranasales, pero no hay evidencia de que el uno sea el causante del otro o que el tratamiento de los síntomas de las vías aéreas superiores o sinusal modificaran la tos eficazmente. Evidentemente, el drenaje post-nasal puede causar sonidos repetitivos para despejar la zona pero eso difiere de una tos verdadera.

\section{CONCLUSIÓN}

La tos crónica puede ser un problema desafiante y frustrante para el paciente, la familia y para el médico al cual se le pide que encuentre una solución para terminar con ella. Una aproximación diagnóstica que combine una historia clínica detallada y la consideración de causas basadas en la evidencia puede proveer rápidamente la etiología en la mayoría de los casos y así permitir la toma de decisiones apropriadas para el tratamiento.

\section{REFERENCIAS}

I. Marchant JM, Newcombe PA, Juniper EF, Sheffield JK, Stathis SL, Chang AB. What is the burden of chronic cough for families? Chest 2008; 134: 303-9.

2. Chang AB, Robertson CF, Van Asperen PP, Glasgow NJ, Mellis $C M A$, et al. A multicenter study on chronic cough in children: burden and etiologies based on a standardized management pathway. Chest 2012; 142: 943-50.

3. Klein NP, Bartlett J, Fireman B, Rowhani-Rahbar A, Baxter R. Comparative effectiveness of acellular versus whole-cell pertussis vaccines in teenager. Pediatrics 2013; 131: el716-22.

4. Knowles MR, Daniels LA, Davis SD, Zariwala MA, Leigh MW. Primary Ciliary Dyskinesia: Recent Advances in Diagnostics, Genetics, and Characterization of Clinical Disease. Am J Respir Crit Care Med 2013 Jun 24 [Epub ahead of print].

5. Cataneo AJ, Reibscheid SM, Ruiz Junior RL, Ferrari GF. Foreign body in the tracheobronchial tree. Clin Pediatr (Phila) 1998; 36: $701-6$

6. Mehdi NF, Weinberger MM, Abu-Hasan MN. Achalasia: unusual cause of chronic cough in children. Cough 2008; 4-6.

7. Gurgel RK, Brookes JT, Weinberger MM, Smith RJ. Chronic cough and tonsillar hypertrophy: a case series. Ped Pulmonol 2008; 43: 1 147-9.

8. Najada A, Weinberger $M$. Unusual cause of cough in a four year-old cured by uvulectomy. Pediatr Pulmonol 2002; 34: | 44-6.

9. Chang $\mathrm{AB}$, Connor FL, Petsky HL, Eastburn MM, Lewindon PJ, $\mathrm{Hall} C$, et al. An objective study of acid reflux and cough in children using an ambulatory pHmetry-cough logger. Arch Dis Child 201 I; 96: 468-72.

10. Chang AB, Lasserson TJ, Gaffney J, Connor FL, Garske LA. Gastrooesophageal reflux treatment for prolonged non-specific cough in children and adults. Cochrane Database Syst Rev 201 I Jan 19.

II. Campanella SG, Asher MI. Current controversies: sinus disease and the lower airways. Pediatr Pulmonol 200 I; 31 : 165-72.

12. Morice $\mathrm{AH}$. Post-nasal drip syndrome-a symptom to be sniffed at? Pulm Pharmacol Ther 2004; 17: 343-5.

13. Kemp A. Does post-nasal drip cause cough in childhood? Paediatr Resp Rev 2006; 7: 31 -5. 